\title{
Exploration and Practice of Smart Classroom in Colleges and Universities
}

\author{
Peiting $\mathrm{Yu}^{1,{ }^{1}}$ Haobing $\mathrm{Wei}^{2}$ Xuan $\mathrm{Zhu}^{2}$ Han $\mathrm{Liu}^{2}$ \\ ${ }^{1}$ Wuhan College of Arts and Science, Wuhan 430000, China \\ ${ }^{2}$ College of Information and Communication, National University of Defense Technology, Wuhan 430010, China \\ *Corresponding author.Email: laure163@163.com
}

\begin{abstract}
In view of the deficiencies in the current teaching of electronic and communication courses in colleges and universities, taking the course of antenna and radio wave propagation as an example, the research and construction of smart classroom are carried out. Firstly, the concept of smart classroom is explained. Secondly, the course content of antenna and radio wave communication are summarized. Thirdly, the system of smart classroom in three aspects of teachers, content and platform are constructed. Fourthly, three stages of the implementation of smart classroom before, during and after class are listed. Lastly, corresponding teaching methods are given. Compared with the traditional teaching mode, under the intelligent classroom teaching mode, students have more interest in learning, more participation and better learning effect. The construction of antenna and radio wave propagation smart classroom provides guidance and reference value for the teaching mode reform of electronic and communication specialty in colleges and universities.
\end{abstract}

Keywords: smart classroom, teaching mode, colleges and universities.

\section{INTRODUCTION}

Smart classroom [1-2] is a new teaching model, which mainly reflects the autonomy, flexibility, diversity and interaction of students' learning. Students use fragmented time to study according to their learning interests and learning requirements. Compared with the traditional cramming teaching, this teaching model is very helpful to improve students' learning effect and learning efficiency.

Smart classroom first emerged abroad. Since 2012, scholars have conducted research in China. Since 2016, it has developed rapidly and relevant literature has been emerging. Peng Yaohui et al. [3] summarized the research status of smart classroom in China, and summarized the research on smart classroom teaching practice, the construction of smart classroom teaching model and the application of teaching platform. Hu Cheng [4] studied the construction of junior middle school mathematics smart classroom based on micro-lectures, and gave a specific example analysis. Huang Xueming [5] practiced the use of smart classroom in mathematics teaching and verified the role of smart classroom in improving teaching effectiveness. Xiao Wei [6] studied the impact of smart classroom on the teaching quality of colleges and universities, and rationally analyzed the advantages and disadvantages of smart classroom. Zhang Yan and others studied the smart classroom teaching mode under the background of new engineering, and summarized the six advantages of smart classroom compared with the traditional teaching mode. Liu Wei [7] discussed the learning strategies in the smart classroom, emphasizing that teachers should keep pace with the times and constantly improve their professional knowledge, ability and computer level. Cheng Erjiu [8] conducted research on the application and efficiency of smart classroom in college teaching. The teaching mode of measuring instrument verification and adjustment of smart classroom constructed by Cheng Erjiu [8] has important reference value and guiding significance for the construction of smart classroom in colleges and universities. Gao Tao et al. [9] proposed a new intelligent classroom teaching mode of case-based programming course, which takes students as the main body and teaches students according to their aptitude, and the teaching results have been significantly improved. Generally speaking, in recent years, smart classroom has developed rapidly and has become a hot research topic for educators, which plays a certain role in promoting the reform of China's educational model. Especially for the teaching of science and engineering courses, the application of smart classroom can get twice the result 
with half the effort under the combination of practice and theory.

For students majoring in electronic communication in science and engineering, antenna and radio wave propagation [10] is a professional compulsory course, which plays a basic supporting role in subsequent jobs and academic research fields. At present, there are few articles to study the teaching reform of antenna and radio wave communication [11-12], especially the teaching reform of antenna and radio wave communication based on smart classroom. At present, there is no literature to study. Therefore, the research and construction of antenna and radio wave communication smart classroom is highly innovative and provides another brand-new teaching idea, which provides a reference for the teaching reform of electronic communication courses.

\section{INTRODUCTION TO ANTENNA AND RADIO WAVE PROPAGATION}

This course is a compulsory course for undergraduates majoring in electronic communication, focusing on mastering the basic concepts, basic principles, basic analysis and calculation methods and engineering application technology of antenna and radio wave propagation.

\subsection{Teaching objectives}

The general goal of course teaching is to enable students to master the basic concepts, basic principles, basic analysis and calculation methods and engineering application technology of antenna and radio wave propagation, so as to consolidate basic knowledge, cultivate basic ability and improve basic quality. It includes knowledge, ability and quality, as shown in figure 1 .

\subsubsection{Knowledge level}

Master the structure and principle of various antennas; Master the mode and characteristics of radio wave propagation.

\subsubsection{Capability level}

Learn basic antenna and radio wave analysis and calculation methods; Have the ability to comprehensively use the knowledge learned to solve practical problems.

\subsubsection{Quality level}

Have strong abstract thinking and model concept, and form good theoretical quality and engineering quality.

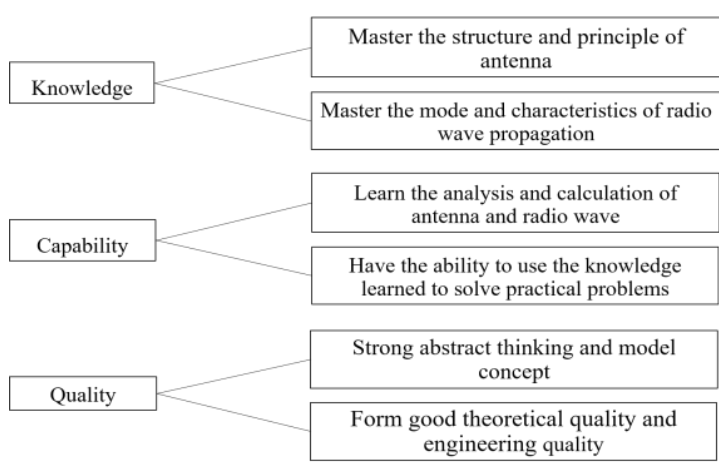

Figure 1 Teaching objectives of antenna and radio wave propagation

\subsection{Teaching concept}

In order to achieve the teaching objectives, the teaching concept of this course is embodied in three aspects: consolidating the technical foundation, highlighting the engineering application and facing the post, as shown in figure 2 .

\subsubsection{Consolidate the technical foundation}

The course focuses on analyzing the basic principles of antenna and radio wave propagation, explaining the basic methods clearly, and practicing typical exercises repeatedly, so as to lay a solid theoretical foundation for subsequent course learning and engineering application.

\subsubsection{Highlight engineering applications}

Aiming at typical engineering application problems, the combination of software and hardware is adopted to analyze and optimize the design of antenna, calculate and measure radio wave propagation, so as to improve students' engineering application ability.

\subsubsection{Position oriented}

The course focuses on the practical application of antenna and radio wave propagation in the job, focuses on cultivating students' ability to analyze antenna and radio wave propagation phenomena and solve antenna and radio wave propagation problems, and provides knowledge and skill reserves for students.

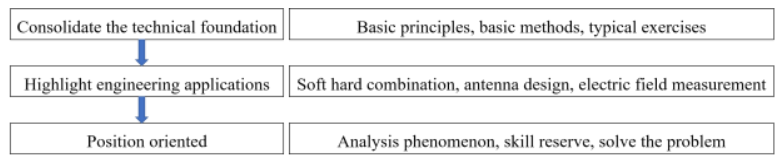

Figure 2 Teaching concept of antenna and radio wave propagation

\subsection{Teaching content}

In order to implement the teaching concept and achieve the teaching objectives, according to the idea from theory to application, the course is provided with 
three topics: antenna theory, radio wave propagation theory and the application of antenna and radio wave propagation theory, as shown in table 1.

The first topic is antenna theory, including the basic analysis method of antenna, the directivity of antenna array, the structural form, working principle and performance characteristics of typical antenna.

The second topic is radio wave propagation theory, including free space radio wave propagation theory, propagation characteristics and analysis and calculation methods of ground wave propagation, sky wave propagation and line of sight propagation.

The third topic is the application of antenna and radio wave propagation theory, including antenna design, simulation and detection, field measurement of radio wave propagation, simulation experiment, etc.

Table 1. Teaching contents of antenna and radio wave propagation

\begin{tabular}{|c|c|c|}
\hline $\begin{array}{l}\text { Special } \\
\text { topics }\end{array}$ & lecture & Content \\
\hline \multirow{4}{*}{$\begin{array}{l}\text { Topic } 1 \\
\text { Antenna } \\
\text { theory }\end{array}$} & Lecture 1 & Antenna overview \\
\hline & Lecture 2 & $\begin{array}{l}\text { Antenna electrical } \\
\text { parameters and } \\
\text { symmetrical oscillator }\end{array}$ \\
\hline & Lecture 3 & Directivity of antenna \\
\hline & Lecture 4 & $\begin{array}{l}\text { Vertical antenna and log } \\
\text { periodic antenna }\end{array}$ \\
\hline \multirow{5}{*}{$\begin{array}{c}\text { Topic } 2 \\
\text { Radio } \\
\text { wave } \\
\text { propagati } \\
\text { on theory }\end{array}$} & Lecture 1 & $\begin{array}{c}\text { Overview of radio wave } \\
\text { propagation }\end{array}$ \\
\hline & Lecture 2 & Ground wave propagation \\
\hline & Lecture 3 & Sky wave propagation \\
\hline & Lecture 4 & Line of sight propagation \\
\hline & Lecture 5 & $\begin{array}{l}\text { Radio wave propagation } \\
\text { in special systems }\end{array}$ \\
\hline \multirow{2}{*}{$\begin{array}{c}\text { Topic } 3 \\
\text { Applicatio } \\
n \text { of } \\
\text { antenna } \\
\text { and radio } \\
\text { wave } \\
\text { propagati } \\
\text { on theory }\end{array}$} & $\begin{array}{l}\text { Assign- } \\
\text { ment } 1\end{array}$ & $\begin{array}{c}\text { Simulation and analysis of } \\
\text { microstrip antenna }\end{array}$ \\
\hline & $\begin{array}{l}\text { Assign- } \\
\text { ment } 2\end{array}$ & $\begin{array}{l}\text { Simulation calculation of } \\
\text { radio wave propagation }\end{array}$ \\
\hline
\end{tabular}

\section{SYSTEM CONSTRUCTION OF SMART CLASSROOM}

Considering the particularity of the course antenna and radio wave propagation, the construction of the smart classroom of antenna and radio wave propagation is mainly divided into the following three aspects: the construction of teachers, the construction of content and the construction of platform.

\subsection{Teacher construction}

Smart classroom has certain requirements for teachers' professional cultural level, teaching level and the application level of information tools. If the level of teachers cannot be guaranteed, the construction of teaching content and teaching platform is empty talk, and the implementation of smart classroom is impossible. Therefore, teacher construction is the basis and key of the construction of the whole smart classroom system.

\subsubsection{In terms of professional and cultural level}

Teachers who teach antenna and radio wave propagation should have a good professional foundation in electronic communication and be able to deeply understand and master the contents of relevant electronic communication courses, such as advanced mathematics, circuits and systems, analog electronic circuits, digital electronic circuits, electromagnetic fields and electromagnetic waves, especially electromagnetic fields and electromagnetic waves, This course is difficult and involves a wide range of knowledge. Therefore, if you want to teach the course antenna and radio wave propagation well, you must first have a solid professional foundation in electronic communication.

\subsubsection{In terms of teaching level}

For the course antenna and radio wave propagation, the teaching objectives, teaching concepts and teaching contents have been introduced in the previous section. This is a course combining theory and practice. Teachers need to have many years of traditional teaching experience and a certain teaching level, master solid theories, and be proficient in operating instruments and equipment. If teachers do not have experience in traditional teaching mode, it is impossible to compare the advantages of smart classroom in this course teaching. In the implementation of smart classroom, we can combine the advantages of traditional classroom and smart classroom to improve the teaching effect.

\subsubsection{In the application of information tools}

The core of smart classroom is embodied in the word smart. The understanding of smart can be regarded as the use of advanced smart teaching mode. Therefore, smart 
classroom refers to the use of advanced smart teaching mode for classroom teaching and learning. Advanced intelligent teaching mode needs the support of information technology and platform, which puts forward certain requirements for teachers to master and use relevant information tools.

\subsection{Content construction}

Antenna and radio wave propagation includes three topics: antenna theory, radio wave propagation theory and the application of antenna and radio wave propagation theory. The first two topics mainly involve theory and have low requirements for practice. Most of the contents can adopt the mode of offline self-study, online Q \& A and fine lecture on key and difficult points. The third topic has more practice and application, involving programming calculation and simulation experiment. It can be carried out in the way of assignment, allowing students to selfstudy before class, complete their homework, and let students summarize the involved principle knowledge; the experimental measurement part allows students to review the principle knowledge involved, carry out experimental operation in class, summarize after class, and connect the principle with practical application, so that students can personally realize that learning is useful. The theory of each part does not exist independently, and the corresponding application scenarios can be found.

\subsection{Platform construction}

The platform construction of smart classroom determines whether the smart classroom can be implemented normally. In the specific implementation process, due to different teachers' different mastery of programming and software development, some liberal arts teachers do not understand the platform development. In this case, they need to rely on relevant technicians to complete it. The instructor raises the demand, and the technicians build the platform according to the teacher's demand. For antenna and radio wave propagation, relevant MATLAB software and HFSS software need to be embedded into the platform, which can be programmed and calculated in real time by MATLAB and call HFSS software for simulation modeling [13].

\section{IMPLEMENTATION OF SMART CLASSROOM}

The implementation of smart classroom is mainly divided into three stages: pre class stage, in class stage and after class stage.

\subsection{Pre class stage}

The teacher uploads the high-quality resources to the platform, the students punch in, select the learning content according to their interests, use the fragmented time to complete the learning, complete the homework assigned by the teacher before class, and upload the learning results to the platform. The main teaching means are: the combination of micro-lectures video and network course. Through the use of information means such as microlectures, video and animation, the abstract concepts and theories are visualized to give students perceptual knowledge; At the same time, the teaching content is supplemented and expanded in combination with the learning of online courses.

\subsection{In class stage}

According to the pre class learning results, the teacher evaluates the students' common mistakes and key problems, gives intensive lectures on these problems, and uses interactive discussion to improve the students' participation and learning interest. The main teaching methods adopted at this stage are as follows. The first is the combination of theoretical teaching and problem discussion. Through the explanation of concepts, the interpretation of theories, the derivation and calculation of processes, and the induction and summary of laws, students should strive to understand concepts, theories, processes and laws. At the same time, classroom discussion is adopted to deepen students' understanding of the knowledge learned in the classroom. The second is the combination of physical analysis and simulation experiment. Through physical analysis, in-situ measurement, simulation experiment and other methods, deepen students' understanding of the learned knowledge and improve students' ability to flexibly use the learned knowledge to solve practical problems.

\subsection{After class stage}

The teacher assigns homework after class, and the students upload the results to the platform. The platform evaluates the students' learning effect and feeds back the evaluation results to the teacher. The teacher dynamically adjusts and improves the whole teaching process according to the evaluation results, so as to form a closed loop of evaluation continuous improvement based on learning results. The main teaching means used in this stage: combining after-school homework and after-school self-study, strengthening the knowledge learned in class through homework, and consolidating and improving the learned content through self-study after class.

The specific implementation process of smart classroom is shown in figure 3.

By adopting smart classroom to teach antenna and radio wave communication, students have higher participation in class, stronger interest in learning, and a higher proportion of completing homework independently. Students can master knowledge in a relaxed and pleasant atmosphere. 


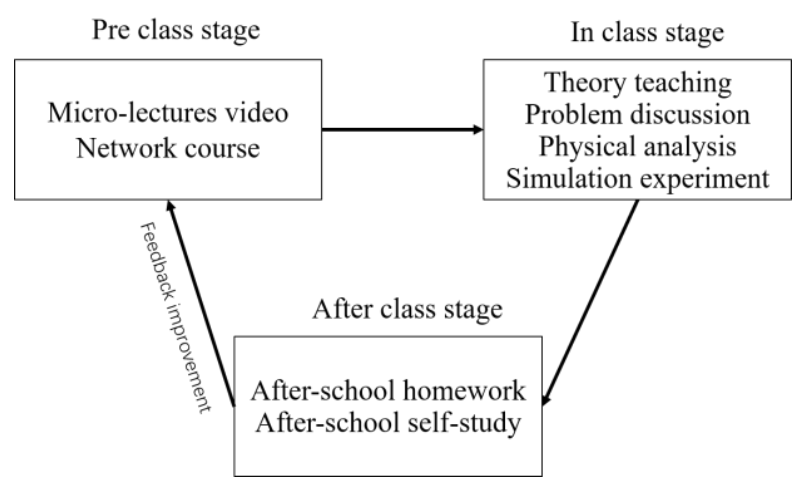

Figure 3 Implementation flow chart of smart classroom

\section{CONCLUSION}

Smart classroom is a new teaching model, which plays a significant role in promoting teaching effectiveness. At present, the teaching of electronic communication courses in colleges and universities mostly adopts the traditional teaching mode, which has some problems, such as students' low interest in learning, and the combination of practice and theory is not close. This paper takes the undergraduate course of antenna and radio wave propagation as an example to study and construct the smart classroom. Through teaching practice, it is proved that applying smart classroom to the teaching of antenna and radio wave propagation can effectively improve students' learning interest, teachers' teaching effect and students' learning effect. The construction of smart classroom of antenna and radio wave propagation provides guiding significance and reference value for the reform of teaching mode of electronic communication specialty.

\section{ACKNOWLEDGMENTS}

Financial support from the Research Program of National University of Defense Technology (No. ZK1906) and Teaching Research Project of College of Information and Communication (No. JY20A003) are gratefully acknowledged.

\section{REFERENCES}

[1] J. Wang, F. An, and Z. Li, Progress and reflection on curriculum and teaching methodology research under the background of internet+, Educational Research, no. 11, pp. 105-116, Nov 2017. DOI: CNKI: SUN: JYYJ.0.2017-11-020

[2] R. Duan, and M. Feng, Research on the construction of foreign language intelligence classroom in the background of internationalization, Theory and Practice of Education, vol. 39, no. 3, pp. 48-50, Mar 2019. DOI: CNKI: SUN: JYLL.0.2019-03-017

[3] Y. Peng, and B. Zhang, Review on the research status of smart classroom in China, Education and
Teaching Research, no. 5, pp. 121-123, May 2019. DOI: CNKI: SUN: JMSJ.0.2019-05-075

[4] C. Hu, Discussion on the construction of junior middle school mathematics smart classroom based on micro-lectures, Science Weekly, no. 21, pp. 153153, Dec 2019. DOI: CNKI: SUN: XZHK.0.201921-148

[5] X. Huang, On the use of smart classroom in Mathematics Teaching, New Teacher, pp. 53-54, Dec 2019.

[6] W. Xiao, Influence of smart classroom on teaching quality in colleges and universities, Science and Education Guide, no. 13, pp. 1-2, Jul 2019.

[7] W. Liu, Discussion on learning strategies in smart classroom environment, Guangdong Vocational and Technical Education and Research, no. 3, pp. 52-54, Mar 2019. DOI: CNKI: SUN: GZJA.0.2019-03-017

[8] E. Cheng, Research on the application and effectiveness of smart classroom in College Teaching, Vocational Technology, vol. 18, no. 6, pp. 60-62, Jun 2019. DOI: CNKI: SUN: ZYJU.0.2019-06-015

[9] T. Gao, X. Feng, and C. Sun, Research on smart classroom teaching of case driven programming course, China Education Informatization, no. 12, pp. 48-51, Dec 2019. DOI: CNKI: SUN: JYXX.0.2019$12-012$

[10] Z. Song, J. Zhang, and Y. Huang, Antenna and radio wave propagation (Third Edition), Xi'an: Xi'an University of Electronic Science and Technology Press, 2016.

[11] J. Hu, L. Zhang, Z. Zhang, and C. Ni, Double truth teaching exploration of antenna and radio wave propagation, Journal of Hefei Normal University, vol. 36, no. 3, pp. 52-53, May 2018. DOI: CNKI: SUN: AFJY.0.2018-03-018

[12] Z. Ye, Q. Li, Y. Shao, and X. Liao, Discussion on the teaching method reform for the course of antennas and radio wave propagation, Education Teaching Forum, no. 3, pp. 159-160, Mar 2018. DOI: CNKI: SUN: JYJU.0.2018-11-072

[13] Z. Duan, Reform and research on the teaching and experimental course of antenna and radio wave propagation, Shandong Industrial Technology, pp. 219-219, Jan 2017. DOI: CNKI: SUN: SDGJ.0.2017-10-191 